\title{
A CORRELATION STUDY BETWEEN CONVENTIONAL LIPID PARAMETERS AND HS-CRP IN CORONARY HEART DISEASE
}

\author{
Rangaswamy R1, Santosh R. G²
}

\section{HOW TO CITE THIS ARTICLE:}

Rangaswamy R, Santosh R. G. "A Correlation Study between Conventional Lipid Parameters and Hs-Crp in Coronary Heart Disease". Journal of Evolution of Medical and Dental Sciences 2015; Vol. 4, Issue 40, May 18; Page: 7042-7047, DOI: $10.14260 /$ jemds/2015/1022

\begin{abstract}
BACKGROUND: Coronary heart disease (CHD) is the most common form of heart disease. Changes in lifestyle, decreased physical activity, dietary modifications etc., in indian population is considered to be the major risk factor. By 2020 it is estimated that it will be the major cause of death in the world. High sensitivity CRP (hs-CRP) test measures very small amounts of CRP in the blood and is helpful even in healthy individuals to assess their potential risk for heart ailments. The hs-CRP levels are directly proportional to extent source of CHD which indicates that the hs-CRP has positive correlation with the disease burden. Hence the present study was undertaken. MATERIAL AND METHODS: The study was done by taking two groups controls and cases between the ages 25-60 years. Fasting blood samples were collected and analysed for estimation of triglycerides, cholesterol, LDL- cholesterol, HDL-cholesterol and hs-crp levels. RESULT: Serum levels of cholesterol, TG, LDL-C, and hs-CRP (p-value 0.0001) were significantly increased and HDL-C (pvalue 0.0002 ) was significantly decreased in cases as compared to healthy controls. CONCLUSION: It is seen that hs-CRP level is significantly elevated in cases (MI patients) than the normal controls. So the present study shows a significant and positive correlation with conventional lipid profile parameters.
\end{abstract}

KEYWORDS: Coronary Heart Disease (CHD), hs-CRP (high sensitivity C-Reactive Protein) , diabetes mellitus, diabetes mellitus with hypertension, myocardial infarction.

INTRODUCTION: C - reactive protein (CRP) was identified by Tillet and Francis (1930) in the plasma of patients with pneumonia and was named for its ability to bind and precipitate the Cpolysaccharide of pneumococcus. Its physiological roles are numerous and varied but has several functions similar to those of immunoglobulins, CRP appears to function in host defense. ${ }^{[1,2]}$ It is an alpha globulin with a molecular mass of approximately 1,10,000 to 1,40,000 daltons, and is composed of five identical subunits, which are noncovalently assembled as a cyclic pentamer.[3] CRP is synthesized in the liver and is normally present as a trace constituent of serum or plasma at levels less than $0.3 \mathrm{mg} / \mathrm{dl} .[4,5,6] \mathrm{CHD}$ is the most common form of heart disease. Changes in lifestyle, decreased physical activity, dietary modifications etc., in Indian population are considered to be the major risk factor for Coronary heart disease (CHD). By 2020 it is estimated that it will be the major cause of death in all regions of the world.[7] Hypertension, diabetes, smoking account for fifty percent of prevalence and severity of the disease.[8] Low Density Lipoprotein (LDL), Triglycerides (TG), High Density Lipoprotein (HDL), Serum Glutamate Oxaloacetate Transaminase (SGOT), etc. do not completely account for the increase in premature CHD in Indian population. ${ }^{[9]}$ So the present study was undertaken for considering the hs-CRP as a cardiac marker for early detection of CHD. 


\section{ORIGINAL ARTICLE}

MATERIAL AND METHODS: After obtaining ethical committee clearance, a total number of 60 subjects were included in the study. The study included 30 controls and 30 cases. Myocardial infarction patients were included in the cases and normal healthy individuals were taken as controls, between the ages 25-60 years. Angiographically confirmed MI patients were considered under inclusion criteria. Pregnant females, chronic liver, kidney disease and known cases of acute and chronic infection, autoimmune diseases were excluded from the study. The control group included healthy non-diabetic and non MI subjects. Informed consent was obtained from all study subjects. Fasting blood samples were collected in plain vacutainers under sterile measures and serum separated was used for analysis for triglycerides,[10,11,12] cholesterol,[13,14] LDL- cholesterol by calculation method and HDL-cholesterol,[15,16,17] levels using semi automated analyser. hs-CRP was estimated using ELISA kit methodology.[18,19] Normal range of TG is $25-200 \mathrm{mg} / \mathrm{dl}$, Cholesterol is $125-200 \mathrm{mg} / \mathrm{dl}$, HDL- cholesterol is $30-65 \mathrm{mg} / \mathrm{dl}$ and LDL- cholesterol is $80-130 \mathrm{mg} / \mathrm{dl}$. Normal range of fasting hs-CRP is up to $3 \mathrm{mg} / \mathrm{L}^{[16,20]}$ Statistical analysis was done using SPSS version 17 statistical software package and Unpaired't' test. Results are expressed as mean \pm SD. p-value $<0.05$ was considered as statistically significant.

\section{RESULTS:}

\begin{tabular}{|c|c|c|c|}
\hline Parameter & Controls (n=30) & Cases (n=30) & *p-value \\
\hline Cholesterol (mg/dl) & $144.40 \pm 7.38$ & $227.86 \pm 18.40$ & 0.0001 \\
\hline Triglycerides (mg/dl) & $125.17 \pm 10.72$ & $203.24 \pm 27.60$ & 0.0001 \\
\hline LDL-C (mg/dl) & $93.14 \pm 6.7$ & $123.60 \pm 15.50$ & 0.0001 \\
\hline HDL-C (mg/dl) & $44.91 \pm 4.82$ & $40.03 \pm 4.51$ & 0.0002 \\
\hline hs-CRP (mg/L) & $1.61 \pm 0.37$ & $5.18 \pm 1.79$ & 0.0001 \\
\hline
\end{tabular}

Table 1: Comparison of various parameters between cases and controls

${ }^{*}$ p-value $<0.05$ - Statistically significant.

Comparative analysis of serum levels of cholesterol, TG, LDL-C, HDL-C and hs-CRP between controls and cases showed that the mean levels of cholesterol, TG, LDL-C, HDL-C and hs-CRP in controls were in the range of $144.40 \pm 7.38 \mathrm{mg} / \mathrm{dl}, 125.17 \pm 10.72 \mathrm{mg} / \mathrm{dl}, 93.14 \pm 6.7 \mathrm{mg} / \mathrm{dl}, 44.91 \pm 4.82$ $\mathrm{mg} / \mathrm{dl}$ and $1.61 \pm 0.37 \mathrm{mg} / \mathrm{L}$ respectively. In cases the mean levels of serum cholesterol, TG, LDL-C, HDL-C and hs-CRP were in the range of $227.86 \pm 18.40 \mathrm{mg} / \mathrm{dl}, 203.24 \pm 27.60 \mathrm{mg} / \mathrm{dl}$, $123.60 \pm 15.50 \mathrm{mg} / \mathrm{dl}, 40.03 \pm 4.51 \mathrm{mg} / \mathrm{dl}$, and $5.18 \pm 1.79 \mathrm{mg} / \mathrm{L}$ respectively. In our study around $30 \%$ of the cases showed elevation in hs-crp levels when their lipid profile parameters were within normal range. Statistical analysis by unpaired t-test shows that mean levels of HDL-C were significantly decreased $(\mathrm{p}<0.05)$ and mean level of serum cholesterol, TG, LDL-C and hs-CRP were significantly increased in cases when compared to healthy controls and are statistically highly significant ( $\mathrm{p}<$ 0.05 ) . In control group values were found within the normal range.

DISCUSSION: CRP is one of the acute-phase proteins. The serum or plasma levels rise during general, nonspecific response to a wide variety of diseases which includes infections by gram positive and negative organisms, acute phase of rheumatoid arthritis, abdominal abscesses, inflammation of the 


\section{ORIGINAL ARTICLE}

bile duct, Guillain-Barre syndrome, multiple sclerosis, certain viral infections, tuberculosis, acute infectious hepatitis, necrotic and inflammatory diseases, burns patients and after surgical trauma. ${ }^{[21,22]}$ Although the detection of elevated levels of CRP in the serum is not specific for any particular disease it is a useful indicator of inflammatory processes.[23] CRP levels rise in serum or plasma within 24 to 48 hours following acute tissue damage, reach a peak during the acute stage (approximately 1000x constitutive level) and decrease with the resolution of inflammation or trauma. The increase of CRP in serum or plasma may last for several days before decreasing to normal levels.[18,24,25] The CRP is a major inflammatory cytokine that functions as a nonspecific defence mechanism in response to tissue injury or infection. High sensitivity CRP (hs-CRP) test measures very small amounts of CRP in the blood and is helpful even in healthy individuals to assess their potential risk for heart ailments. It measures CRP in the range from 0.5 to $10 \mathrm{mg} / \mathrm{L}$. Normally CRP test is done for patients at risk for infections or chronic inflammatory diseases. It measures CRP in the range from 10 to $1000 \mathrm{mg} / \mathrm{L}$. The rate of CRP synthesis is influenced by the cytokines involved in the inflammatory process.[26,27] It was observed that hs-CRP was significantly elevated in patients dying suddenly with severe CAD, both with and without acute coronary thrombosis, and it was correlated with immunohistochemical staining (HIS) intensity and number of thin cap atheroma.[28] Roy et al, in 2005, did a comparative study of markers of inflammation for the assessment of cardiovascular risk in patients with acute chest pain. Estimation of albumin concentration, leukocyte count and hs-CRP was measured. Results showed lower albumin concentration, higher leukocyte count and high level of hs-CRP. Study concluded that leukocyte count is an independent predictor of ACS and high hs-CRP levels is an independent predictor of clinical outcome in ACS patients.[29] Dr. Soinio et al., study results showed patients with hs-CRP levels $>3.0 \mathrm{mg} / \mathrm{dl}$ had a higher CHD mortality rate than patients with hs-CRP $<3.0 \mathrm{mg} / \mathrm{dl}$. The results were similar when the patients who have no history of MI were analysed. Independent risk posed by elevated hs-CRP levels in diabetic patients suggests that inflammation plays an important role in fatal CHD events among the high risk population.[30] Takahashi Kenji et al in 2006, have shown in their study that inflammation is closely related not only to insulin resistance but also to macro-angiopathy in type- 2 diabetic patients, and hsCRP can be useful marker for evolution of pathophysiology in type-2 diabetes mellitus or vascular lesion.[31]

Takahashi et al and Pfutzner Forst in 2006, noted that elevation of hs-CRP was associated with increased risk of type-2-diabetes development in patients with all levels of metabolic syndrome.[32] Nyandak et al study in 2007 shows that hs-CRP levels were elevated in angiographically confirmed CAD patients. hs-CRP levels were higher in acute coronary syndrome patients compared to patients with normal coronary angiograms. The hs-CRP levels are directly proportional to extent source of CAD which indicates that the hs-CRP has positive correlation with the disease burden in CVD patients. ${ }^{[33]}$ A pilot study was carried out by Suman B. Sharma in 2008 on hs-CRP and oxidative stress in young CAD patients in India. Study concluded that elevated hs-CRP levels along with dyslipidemia and oxidative stress added to the predictive value of premature CAD in Indian population. ${ }^{34]}$ Increasing hs-CRP level suggests that the chronic inflammation that leads the progression of atherosclerosis and atherothrombosis is a causative factor for CHD. Many evidences indicate that inflammation of hs-CRP may lead to the development of type II diabetes and the progression of atherosclerosis. It is also etiologically involved in the pathogenesis of diabetes and is considered as an important cardiovascular risk marker in patients with diabetes mellitus.[35] The comparative study between type-2-diabetic patients and non-diabetic patients revealed that type-2-diabetic patients 
were at higher risk for CHD when classified into low, intermediate, and high risk group based on hsCRP levels.[36] Further studies are required involving larger population to establish the different risk groups of Indian population.

CONCLUSION: It is seen that hs-CRP level is significantly elevated in cases (MI patients) than the normal controls. It is concluded that there is positive correlation between conventional lipid parameters and hs-crp in CHD. Major limitation of the study is the sample size. Study with larger group may be required for further evaluation.

ACKNOWLEDGEMENT: We would like to acknowledge the Cardiology and Medicine department, the patients and paramedical staff and to the institution for their kind support.

\section{REFERENCES:}

1. Schultz D.R, and Arnold P.I.: "Properties of four acute phase proteins: C-reactive protein, serum amyloid A protein, glycoprotein, and fibrinogen." Seminars in Arthritis and Rheumatism 1990; 20: $129-147$ pg.

2. Kindmark C.O, The Concentration of C-reactive protein in Sera from Healthy Individuals. Scand J. Clin Lab Invest, 1972; 29 (4): 407- 411 pg.

3. Dowling P, and Cook S. Immune events in demyelinating disease. In Wolfgang F, Ellison G.W, Stevens J.G, and Andrew J.M. (eds.). Multiple sclerosis. Academic Press Inc. New York, 1972; 269-277 pg.

4. Yudkin J. S, et al. C - reactive protein in Healthy Subjects: Association with Obesity, Insulin Resistance, and endothelial dysfunction. A potential role for cytokines originating from adipose tissue? Arterioscler Thromb Vasc Biol, 1999; 19: 972-8 pg.

5. Kushner I, Rzewnicki D. L. The acute phase response: General aspects. Bailliere's Clinical Rheumatology, 1994; 8: 513-530 pg.

6. Macy E.M, Hayes T.E, and Tracy R.P. Variability in the measurement of C-reactive protein in healthy subjects: implications for reference interval and epidemiological applications. Clin Chem, 1997; 43; 1: 52-58 pg.

7. Gupta O.P, Phatak S. Rev article. 2003; 23 (2): 37-50 pg.

8. Rajasekhar D, Saibaba K.S.S, Srinivas R, Latheef S.A.A, and Subramanyan G. In J. clini Bio, 2004; 19 (2): 53-59 pg.

9. Burman A, Jain K, Gulati R, Chopra V, Agrwal D.P, Vasisht. 2004, JAPI; 52: 99-102 pg.

10. Trinder P. Ann Clin. Biochem, 1969; 6: 24.

11. Bucolo G, David H. Clin. Chem, 1973; 19: 476.

12. Fossati P, Prencipe L. Clin. Chem, 1982; 28: 2077.

13. Allain C. C, Poon L. S, Chan C. S. G, Richmond W and Fu P, Clin. Chem, 1974; 20: 470.

14. Roeschlau P, Bernt E, and Gruber W. A, Clin. Chem. Clin Biochem 1974: 12: 226.

15. Expert Panel on Detection, Evaluation and Treatment of High Blood Cholesterol in Adults (Adult Treatment Panel III), Executive Summary of the Third Report of the National Cholesterol Education Program (NCEP), JAMA 2001; 285 (19): 2486-2497 pg.

16. "Clinical Guide to Laboratory Tests" Edited by N. W. Tietz, 3rd Edition. W.B Saunders Company (USA), Philadelphia, P. A. 19106 (1995). 


\section{ORIGINAL ARTICLE}

17. Young D S. Effect of drugs on Clinical Lab. Tests. $4^{\text {th }}$ ed. AACC Press. 1995.

18. Shine B, de Beer F. C, and Pepys M. B. Solid phase radiommunoassays for human C-reactive protein. J. Lab Clinica Chimica Acta 1981; 117: 13-23 pg.

19. Votila M. et al. Immunol Methods, 1981; 42: 11.

20. Rekha Bhagwat, Arpita Gupte and Yadav K.S. (2012). Diagnostic Utility of hs-Crp in Coronary Heart Disease. International Journal of Molecular Biology, ISSN: 0976-0482 \& E-ISSN: 09760490, Volume 3, Issue 1, 2012, 36-39 pg.

21. Hedlund P. Clinical and experimental studies on C-reactive protein (acute phase protein). Thesis Acta Med Scand, 1961; 128 (Suppl. 361): 1-71 pg.

22. Hedlund P. The appearance of acute phase protein in various diseases. Acta Med Scand, 1947; 128, (Suppl. 196): 579-601 pg.

23. Morley J.J, Kushner I,: Serum C-reactive Protein Levels. in: Kushner I, Volanakis J.E, and Gerwutz H eds, C-Reactive Protein and the Plasma Protein Response to Tissue Injury. Annals of N.Y. Acad Sci, 1982; 389: 406-417 pg.

24. Kushner I. "C-reactive protein in rheumatology," Arthritis Rheum, 1991; 34: 1065-1068 pg.

25. Dixon J.S et al. C-reactive protein in the serial assessment of disease activity in rheumatoid arthritis. Scand J Rheum. 1984; 13: 39- 44 pg.

26. Thompson D, Pepys M.B, Wood S.P. 1999; structure 7 (2): 169-77 pg.

27. Peter J, Kennelly, Murray, Robert F, Victor W, Rodwell, Kathleen M, Botham. 2009 Harper's illustrated biochemistry.

28. Burke Allen P, Russell P, Tracy, Frank kologies, et al. Circulation, 2002; 105: 2019-2023 pg.

29. Roy D, Quiles J etal. The N. England Journal of Medicine, 2006; 109: 317-321 pg.

30. Soinio M, Mamiemi J, Laakso M etal. Care, 2006; 29: 329-333 pg.

31. Kenji T, Takahero S, Japan- Science link Japan, 2006; 68, 119-122 pg.

32. Pfutzner A, Forst T. Diabetes Technol Ther, 2006; 8 (1): 28-36 pg.

33. Nyandak T, Gogna Arun, Bansal S et al. Indian Journal of Clinical Biochemistry, 2007; 8 (3): 217$221 \mathrm{pg}$.

34. Sharma S.B, Garg S, Garg V.A and Dwivedi S. Indian Journal of Clinical Biochemistry, 2008; 23 (4), 334-336 pg.

35. Khan D.A, Qayyum S. J. Med Sci., 2009; 25: 776-781 pg.

36. David M, Capuzzi and Jefferey S. Freeman Clin Diabetes, 2007; 25: 16-22 pg. 


\section{ORIGINAL ARTICLE}

\section{AUTHORS:}

1. Rangaswamy R.

2. Santosh R. G.

\section{PARTICULARS OF CONTRIBUTORS: \\ 1. Assistant Professor, Department of Biochemistry, Koppal Institute of Medical Sciences, Koppal, Karnataka. \\ 2. Assistant Professor, Department of Medicine, Kannur Medical College, Kannu, Kerala.}

FINANCIAL OR OTHER COMPETING INTERESTS: None

\section{NAME ADDRESS EMAIL ID OF THE} CORRESPONDING AUTHOR:

Dr. Rangaswamy R, Assistant Professor, Department of Biochemistry, Koppal Institute of Medical Sciences, Koppal, Karnataka.

E-mail: rangaswamyr79@yahoo.com

Date of Submission: 25/04/2015.

Date of Peer Review: 26/04/2015.

Date of Acceptance: 11/05/2015.

Date of Publishing: 16/05/2015. 